\title{
Visão de Mundo Ecológica na Educação Matemática: tópicos de Teoria do Caos no estudo da função quadrática
}

\author{
An Ecologic World view in Math Education: some topics in Chaos Theory in the study \\ of quadractic function
}

Tânia Baier

taniabaier@gmail.com

\begin{abstract}
Resumo
Este artigo apresenta aspectos históricos relacionados com pesquisas científicas contemporâneas, sendo explicitadas compreensões acerca da visão de mundo subjacente, conhecida como pensamento ecológico ou pensamento sistêmico. No texto é destacado que, para assumir a visão de mundo ecológica no ensino da Matemática, não é necessária a substituição de conteúdos que constituem a grade curricular, mas sim a mudança no modo de abordá-los. Exemplificando, é enfocada uma atividade didática envolvendo a função quadrática, sendo sugerido um modo de abordá-la assumindo a visão de mundo fenomenológica.
\end{abstract}

Palavras-chave: Ensino de Matemática; Pensamento Ecológico; Fenomenologia.

\begin{abstract}
This paper presents some historic aspects related to current scientific research and clarifies some understandings about the underlying world view, known as ecologic thought or sistemic thought. The text highlights that, in order to achieve the ecologic world view in Math teaching, it's not necessary to replace the contents of the curriculum, but instead, to change the way those are approached. As an example, a didactic activity is emphasized, which involves the quadractic function, giving a suggestion about how to approach it when assuming the phenomenological worldview.
\end{abstract}

Keywords: Math teaching; Ecologic Thought; Phenomenology.

\section{Introdução}

Durante a realização do VI Seminário Internacional de Pesquisa em Educação Matemática (VI SIPEM-edição 2015), na reunião do grupo de trabalho gt11-Filosofia da Educação Matemática, foi apresentada uma análise filosófica sobre os conteúdos matemáticos enfocados na educação básica no Brasil, sendo relatados alguns aspectos históricos e evidenciadas as visões de mundo intrínsecas. O presente artigo está relacionado com o texto apresentado e discutido com os participantes do GT11 e traz aspectos históricos relacionados com pesquisas científicas contemporâneas, sendo explicitadas compreensões acerca da visão de mundo subjacente, conhecida como pensamento ecológico ou pensamento sistêmico.

Neste artigo é destacado que, para assumir a visão de mundo ecológica no ensino da Matemática, não é necessária a substituição de conteúdos que constituem a grade curricular, mas sim, a mudança no modo de abordá-los. Exemplificando, é enfocada uma atividade 
didática envolvendo a função quadrática, sendo sugerido um modo de abordá-la assumindo a visão de mundo fenomenológica.

\section{Visão de mundo ecológica/sistêmica: aspectos históricos e filosóficos}

A compreensão científica de problemas que não podem ser entendidos isoladamente por estarem interligados e interdependentes, na ciência do século XX, recebe denominações diversas: visão de mundo holística, organísmica, ecológica ou sistêmica. O bioquímico Lawrence Henderson foi o primeiro a utilizar o termo sistema para denominar tanto organismos vivos como sistemas sociais. "Dessa época em diante, um sistema passou a significar um todo integrado cujas propriedades essenciais surgem das relações entre suas partes e, pensamento sistêmico, a compreensão de um fenômeno dentro do contexto de um todo maior" (CAPRA, 1998, p. 39, grifos do autor).

Capra (1998, p. 93) relata resultados de pesquisas realizadas em diversas áreas do conhecimento, norteadas pelo pensamento sistêmico, que revelam interligações e interdependências entre os fenômenos e complexas redes de laços de realimentação, os quais “[...] ligam conjuntamente sistemas vivos e não-vivos. Não podemos mais pensar nas rochas, nos animais e nas plantas como estando separados uns dos outros". A Natureza, na visão de mundo fenomenológica, também é entendida como uma totalidade, conforme explicita Merleau-Ponty (2000, p. 120): “[...] não há corte decisivo entre a pedra e o animal, entre o animal e o homem [...]. Nesse sentido, tudo é Natureza, tudo está unido à Natureza, ligado a ela, colocado nela".

$\mathrm{Na}$ atualidade dissemina-se o entendimento da existência de uma íntima interligação entre todos os fenômenos. Diante da utilização desenfreada dos recursos naturais, o tema Ecologia tem sido destaque na mídia e, no mundo escolar, ocorrem ações pedagógicas visando o aprendizado de atitudes de zelo pela preservação do meio ambiente. No entanto, enquanto o ser humano acreditar que pequenos atos de agressão à natureza são inofensivos, enquanto se entender separado dos outros seres que também estão no mundo, continuará agredindo os lugares onde vive. Uma atitude “[...] ecológica somente surgirá quando aliarmos ao nosso conhecimento racional uma intuição da natureza não-linear de nosso meio ambiente" (CAPRA, 2000, p. 39). O autor esclarece:

Nos sistemas lineares, pequenas mudanças produzem pequenos efeitos, e grandes efeitos se devem a grandes mudanças ou a uma soma de muitas pequenas mudanças. Em sistemas não-lineares, ao contrário, pequenas mudanças podem ter efeitos dramáticos, pois podem ser amplificadas repetidamente por meio de realimentação de auto-reforço. (CAPRA, 1998, p. 107) 
O trabalho pioneiro na teoria hoje conhecida como caos foi realizado por Henri Poincaré (1860-1934), ao buscar a solução do problema dos três corpos, que permanecia sem solução desde a época de Newton. A investigação de Poincaré mostra que modelos quantitativos, por mais precisos que sejam, não garantem o alcance de previsibilidade absoluta e sistemas descritos por leis determinísticas nem sempre atuam de modo previsível e regular. Poincaré pesquisou situações de uma “[...] complexidade absolutamente inesperada e demonstrou que as equações da dinâmica podem produzir movimentos extremamente irregulares, sendo estes mais a regra do que a exceção" (EKELAND, 1993, p. 55).

Na década de 1960, Edward N. Lorenz investigou as equações matemáticas para modelar o clima atmosférico, procurando desenvolver um modelo de simulação das condições atmosféricas com o objetivo de elaborar previsões meteorológicas precisas. Lorenz escolheu equações que expressam relações envolvendo, por exemplo, pressão atmosférica, temperatura, velocidade dos ventos e das correntezas marítimas, aplicando as leis científicas tradicionais. Seguindo os princípios do determinismo absoluto das leis físicas newtonianas, Lorenz fundamentou a sua pesquisa no entendimento de que, uma vez encontradas as equações que regem o clima, seria possível prever o tempo atmosférico com precisão. Os meteorologistas dessa época entendiam que, sendo possível, por exemplo, calcular trajetórias de planetas e satélites artificiais e prever eclipses e marés, então também seria possível modelar matematicamente o clima atmosférico e efetuar previsões exatas (BAIER, 2005).

Lorenz descreveu a sua pesquisa, realizada na década de 1960, enfatizando o momento quando, ao digitar 0,506 ao invés de 0,506127 , observou a sua nova simulação computacional do clima atmosférico divergir rapidamente da anteriormente obtida. Percebeu que seu modelo, apesar de ser construído com equações determinísticas, tornava-se imprevisível. "Os erros iniciais de arredondamento eram os culpados, eles estavam regularmente se ampliando até que dominaram a solução. Na terminologia atual, produziu-se o caos" (LORENZ, 1996, p. 166).

Esse fenômeno, uma das principais características da área da ciência que veio a ser chamada teoria do caos, é denominado no meio científico como dependência sensível das condições iniciais e popularmente conhecido como efeito borboleta. Edward Lorenz (1996, p. 28 , grifos do autor) tece algumas considerações sobre a denominação efeito borboleta: “A expressão tem uma história meio obscura. Parece ter surgido logo após a publicação de um artigo que apresentei em um encontro na cidade de Washington, em 1972, intitulado O bater de asas de uma borboleta no Brasil desencadeia um tornado no Texas?".

$\mathrm{Na}$ década de 1960, o ecologista matemático Robert May realiza as primeiras investigações em dinâmica de populações. Ele conduz suas pesquisas sob uma hipótese 
diferenciada daquela assumida no estudo de populações segundo os pressupostos convencionados durante a construção da ciência moderna, estabelecidos por Galileu, Newton e seguidores. Lorenz (1996, p. 181) apresenta o entendimento de May:

A hipótese convencional é que, se a população é muito pequena, ela se multiplicará
livremente, produzindo uma população bem maior, mas ainda bastante pequena, no
próximo ano. Se ela é muito grande, ela irá se reproduzir ainda mais, mas não haverá
alimento suficiente para mantê-la viva, e novamente no próximo ano a população
será pequena. Então, um ano com população maior deverá ser sucedido por um ano
com uma população de tamanho médio. May achava que, para uma taxa adequada
de multiplicação e morte por inanição, o tamanho da população flutuaria
caoticamente.

Em estudos sobre interação entre diferentes espécimes e na disseminação de epidemias, os dados numéricos extraídos de observações mostram um comportamento complexo. Dificuldades surgem na busca de modelos matemáticos que descrevam tais situações, uma vez que as equações tradicionais, sustentadoras das teorias clássicas da Física, se revelam inadequadas para descrever a complexidade dos fenômenos da vida. No decorrer da criação da ciência moderna, coleções de dados irregulares haviam sido obtidas nas mais diversas circunstâncias, sendo explicadas, por exemplo, como consequência da pouca precisão de aparelhos, abandonando-se a pesquisa. A partir das investigações de Robert May, as equações matemáticas envolvendo comportamento irregular despertam interesse entre os ecologistas, uma vez que possibilitam associações com a biologia populacional.

Em sua investigação sobre a dinâmica populacional de limântrias, May verifica que, de modo similar a outros insetos, o número de indivíduos de um determinado ano depende do seu número no ano anterior. Variações anuais são significativas uma vez que tais insetos limitam-se a uma única época do ano para reproduzirem-se, de modo que as gerações ficam diferenciadas, não acontecendo gerações que se sobrepõem. Nas investigações efetuadas por May não prevalece a lógica que perpassa o pensamento científico clássico, a saber, que pequenos insumos produzem pequenas diferenças e grandes insumos produzem grandes modificações.

Capra (1998, p. 65) relata que, na história do pensamento sistêmico, a emergência espontânea de ordem em sistemas complexos, aparentemente aleatórios, é constatada nas pesquisas iniciais em Cibernética, sendo que um dos aspectos mais importantes dos estudos “[...] a respeito dos laços de realimentação é o reconhecimento de que eles retratam padrões de organização [...]. Laços de realimentação são padrões abstratos de relações embutidos em estruturas físicas ou nas atividades de organismos vivos".

As ideias iniciais da Cibernética são aprimoradas em pesquisas posteriores, durante as décadas de 1970 e 1980, que exploram o fenômeno da auto-organização, resumidamente 
descrita como sendo "[...] a emergência espontânea de novas estruturas e de novas formas de comportamento em sistemas abertos, afastados do equilíbrio, caracterizados por laços de realimentação internos e descritos matematicamente por meio de equações não-lineares" (CAPRA, 1998, p.80).

Capra (1998, p. 107) explicita que, desde o início da construção da ciência da Ecologia, as comunidades ecológicas têm sido concebidas como reuniões de organismos ligados à maneira de rede, constatando que, durante as últimas décadas do século $\mathrm{XX}$, dissemina-se o entendimento de que, na natureza, proliferam os fenômenos não lineares, os quais “[...] constituem um aspecto essencial dos padrões de rede dos sistemas vivos. A teoria dos sistemas dinâmicos é a primeira matemática que permite aos cientistas lidar com a plena complexidade desses fenômenos não-lineares". $\mathrm{Na}$ atualidade, os ecossistemas são considerados redes de organismos, entendidos como redes de células, órgãos e sistemas de órgãos. Na natureza: "A teia da vida consiste em redes dentro de redes. Em cada escala, sob estreito e minucioso exame, os nodos da rede se revelam como redes menores [...]. Há somente redes aninhadas dentro de outras redes" (CAPRA, 1998, p. 45).

Refletindo sobre a Natureza e o corpo humano nesses estudos, Merleau-Ponty (2000, p. 332, grifos do autor) busca uma “[...] explicação do Ser, isto é, não a exibição de um Ser, mesmo infinito, no qual se processa - de um modo que, em princípio, nos é incompreensível a articulação recíproca dos seres [...]. Não se trata mais de ordenar as nossas razões mas de ver como tudo isso se mantém junto".

$\mathrm{O}$ entendimento de sistemas vivos interligados e interdependentes acontece em vários momentos no decorrer da história. Capra (2000, p. 403) identifica no taoismo uma das mais profundas expressões de sabedoria ecológica, considera que uma filosofia de fluxo e mudança é ensinada no século V a.C. por Heráclito, que Francisco de Assis defende pontos de vista profundamente ecológicos e explicita: “A sabedoria da ecologia profunda também é evidente em muitas obras da filosofia ocidental, incluindo as de Baruch Spinoza e Martin Heidegger. É encontrada em toda cultura americana nativa e foi expressa por poetas".

A visão de mundo ecológica demanda a superação do entendimento do ser humano como separado dos seres do mundo. Buscando clarificar a essência humana, Heidegger investiga a mitologia grega onde os antigos gregos tentaram expor o mistério da existência. $\mathrm{O}$ mito relata uma história verdadeira no sentido de que se refere profundamente ao homem. A mitologia grega identifica em cada aspecto do cotidiano um enlaçamento com os grandes ciclos da vida. Os gregos conferiram aos seus deuses a figura humana, sem desligá-los da ordem da natureza e das coisas da vida. No mundo dos deuses helênicos há vida exuberante; 
nele, tanto o bem como o mal, tudo está igualmente divinizado, numa totalidade irredutível. As narrativas mitológicas, constituídas geração após geração, apresentam imagens acessíveis a todas as idades, a todas as culturas, em todos os tempos. O mito é a expressão da interioridade humana e nisso reside a sua verdade: "O mito expressa o mundo e a realidade humana, mas cuja essência é efetivamente uma representação coletiva, que chegou até nós através de várias gerações [...]. Decifrar o mito é, pois, decifrar-se” (BRANDÃO, 1991, p. 36).

Da mitologia grega, Heidegger (1998, p. 263) traz a fábula de Cura, apresentada em sua obra Ser e Tempo:

\begin{abstract}
Certa vez, atravessando um rio, Cura viu um pedaço de terra argilosa: cogitando, tomou um pedaço e começou a lhe dar forma. Enquanto refletia sobre o que criara, interveio Júpiter. A Cura pediu-lhe que desse espírito à forma de argila, o que ele fez de bom grado. Como a Cura quis então dar seu nome ao que tinha dado forma, Júpiter a proibiu dizendo que devia dar-se-lhe o seu. Enquanto Cura e Júpiter disputavam sobre o nome, surgiu também a Terra (Tellus) querendo dar o seu nome, uma vez que havia fornecido um pedaço de seu corpo. Os disputantes tomaram Saturno como árbitro. Saturno pronunciou a seguinte decisão, aparentemente eqüitativa: Tu, Júpiter, por teres dado o espírito, deves receber na morte e tu, Terra, por teres dado o corpo, deves receber o corpo. Como, porém, foi a Cura quem primeiro o formou, ele deve permanecer à Cura, enquanto viver. Como, no entanto, sobre o nome há disputa, ele deve se chamar homo, pois foi feito de hummus (Terra).
\end{abstract}

Buscando o sentido fenomenológico de cura, Bicudo (1998, p. 22) considera a fábula da cura e apresenta as possíveis interpretações para compreender-se o homem como cura, ou como cuidado, ou Dasein heideggeriano, ou, o ser-no-mundo-com-os-outros, ou o ser da presença, sendo que no mito da Cura está presente “[...] a realidade do homem (homo), desnudada como corpo (humus) e espírito (Júpiter), porém não retendo a dicotomia corpoespírito e, sim, desvelando o que é essencial à vida mundana desse ente feito de terra e de espírito, que é a cura". A autora esclarece que a palavra cura pode significar "[...] cuidado, sendo cuidado entendido como estar-atento, lúcido ao próprio poder-ser do homem, cuidando para que ele seja, mantendo-se vivo [...]. Cura, como dedicação, significa doação, dar-se ao projeto da manutenção da vida" (BICUDO, 1998, p. 22, grifos da autora).

Assumindo o modo de ser cuidadoso, a abordagem dos conteúdos matemáticos vem relacionada com as questões ecológicas. A seguir é apresentada uma atividade didática, envolvendo o tema função quadrática, relacionada com as investigações iniciais, durante a década de 1960, do ecologista matemático Robert May sobre dinâmica de populações. A abordagem do modelo estudado por May possibilita um entendimento da dependência sensivel das condições iniciais, denominação técnica do efeito borboleta, uma propriedade essencial dos fenômenos caóticos. 


\section{A visão ecológica no ensino de Matemática: abordando tópicos da teoria do caos no estudo da função quadrática}

Os Parâmetros Curriculares Nacionais (BRASIL, 1998, p. 25) apontam que o advento de uma multiplicidade de teorias matemáticas evidenciou não existir um caminho único ligando a matemática e o mundo físico. "Além disso, essa multiplicidade amplia-se, nos tempos presentes, com o tratamento cada vez mais importante dos fenômenos [...] relacionados com as noções matemáticas de caos e de conjuntos fractais". O documento destaca a importância destas novas teorias, mas não indica modos como abordá-las durante o estudo dos conteúdos matemáticos elencados para compor o currículo. Uma possibilidade de abordar tópicos da teoria do caos é realizar a iteração da função quadrática.

"Matematicamente, um laço de realimentação corresponde a um tipo especial de processo não-linear conhecido como iteração (palavra que em latim significa repetição) na qual uma função opera continuamente sobre si mesma" (CAPRA, 1998, p. 107, grifos do autor). Iterar, em geral, significa repetir. Processos iterativos acontecem em diversas situações. Por exemplo, operações bancárias envolvendo juros são iterativas; os gregos usaram iteração para obter melhores aproximações para o valor de $\pi$, iterações geométricas produzem fractais. Iterar o botão de uma calculadora significa entrar com um número qualquer diferente de zero e apertar o botão referente a uma função matemática diversas vezes. Podem ser iteradas construções geométricas ou expressões algébricas.

No estudo do tema função quadrática usualmente são traçados os gráficos com a forma de parábolas e realizados cálculos para a determinação das coordenadas do vértice e dos pontos de intersecção com os eixos cartesianos. A atividade didática a seguir descrita consiste em uma complementação ao estudo tradicional do tema função quadrática assumindo a visão de mundo subjacente à criação da ciência da Ecologia (BAIER, 2005).

Modelos gerais discretos da dinâmica de populações podem ser formulados por meio de equações da forma $\mathrm{P}_{\mathrm{n}+1}=\mathrm{f}\left(\mathrm{P}_{\mathrm{n}}\right)$. No modelo logístico discreto, sendo a população relativa representada por $\mathbf{x}_{\mathbf{n}}$, para evidenciar que a equação é iterada, utiliza-se a notação: $\mathbf{x}_{\mathbf{n}+\mathbf{1}} \rightarrow \mathbf{k} \mathbf{x}_{\mathbf{n}}$ $\left(\mathbf{1}-\mathbf{x}_{\mathbf{n}}\right)$. Conhecendo-se a constante ambiental $\mathbf{k}$ e a população relativa $\mathbf{x}_{\mathbf{n}}$ em certo período de tempo, pode-se calcular a população relativa $\mathbf{x}_{\mathbf{n}+\mathbf{1}}$ nos períodos seguintes, iterando-se sucessivamente, para investigar a variação da população ao longo do tempo. Para mostrar como o caos acontece no mapeamento logístico é utilizado o processo de iteração. Investigar uma população que varia com o passar do tempo, por meio de um processo iterativo, equivale a aplicar uma mesma função repetidamente. Em outras palavras, o conceito de iteração está relacionado com o tema, estudado no ensino médio, denominado função composta. 
A complexidade do mapa logístico $\mathbf{x}_{\mathbf{n}+\mathbf{1}} \rightarrow \mathbf{k} \mathbf{x}_{\mathbf{n}}\left(\mathbf{1}-\mathbf{x}_{\mathbf{n}}\right)$ pode ser percebida com a atribuição de diferentes valores para o parâmetro $\mathbf{k}$, o qual depende das condições ambientais da região estudada. Efetuando iterações sucessivas, pode ser observada a evolução de uma população durante longos períodos. A realização de um imenso número de cálculos, efetuados com o auxílio de computador, revela a emergência de padrões inusitados.

Efetuando a iteração de $\mathbf{x}_{\mathbf{n}+\mathbf{1}} \rightarrow \mathbf{k} \mathbf{x}_{\mathbf{n}}\left(\mathbf{1}-\mathbf{x}_{\mathbf{n}}\right)$ e aumentando progressivamente os valores do parâmetro $\mathbf{k}$, para $0<\mathbf{k}<1$ pode ser observado que todas as órbitas convergem para 0 , sendo que esses resultados mostram que a população tende para a extinção. Aumentando o parâmetro k, como a população tem condições favoráveis para crescer, observa-se que as sucessivas iterações convergem para um estado de equilíbrio.

O processo de iteração também pode ser representado geometricamente por meio da construção de um diagrama de rede, também denominado diagrama de teia de aranha. A figura 1 mostra o diagrama de rede obtido tomando o valor inicial $\mathrm{x}_{0}=0,1 \mathrm{e} \mathbf{k}=2,8$.

Figura 1: Diagrama da teia de aranha correspondente a $\mathbf{x}_{n+1} \rightarrow \mathbf{2 , 8} \mathbf{x}_{n}\left(\mathbf{1}-\mathbf{x}_{\mathbf{n}}\right)$

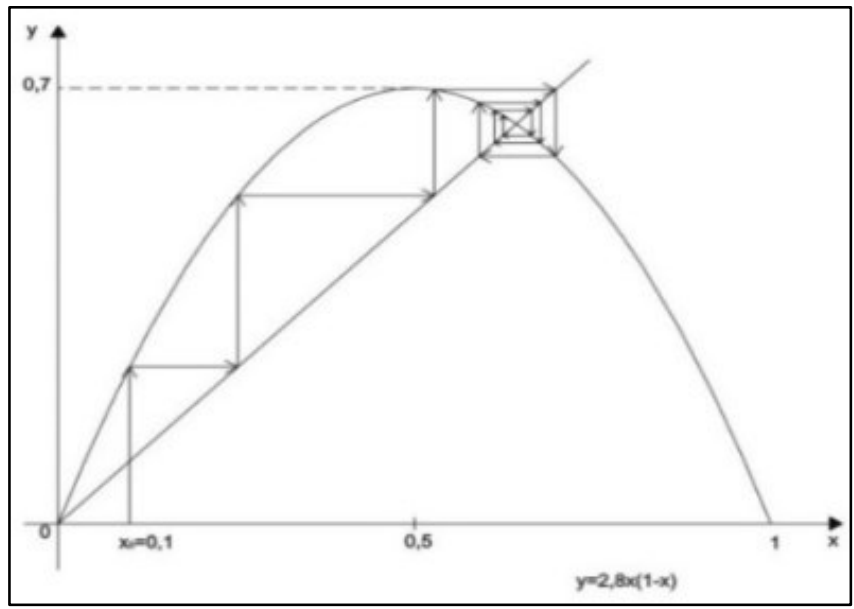

Fonte: Tânia Baier (2005, p.107)

Diferentes diagramas de teia são obtidos quando variam os valores iniciais e os valores do parâmetro $\mathbf{k}$. Os resultados obtidos por meio do cálculo de um grande número de órbitas podem ser representados em um diagrama onde os valores do parâmetro k são representados sobre uma linha horizontal, aumentando da esquerda para a direita, sendo a população relativa plotada sobre o eixo vertical. Com a utilização de computadores pode-se observar que, a partir de 3,5699456... o modelo logístico apresenta um comportamento bastante complexo, sucedendo-se regiões caóticas e periódicas. Na parte direita da figura 2, observa-se que as 
regiões caóticas, onde existe dependência sensitiva às condições iniciais, encontram-se entremeadas por janelas de periodicidade, que podem ser vistas como regiões mais claras.

Figura 2: Mapeamento logístico para valores de $\mathbf{k}$ entre 0 e 4

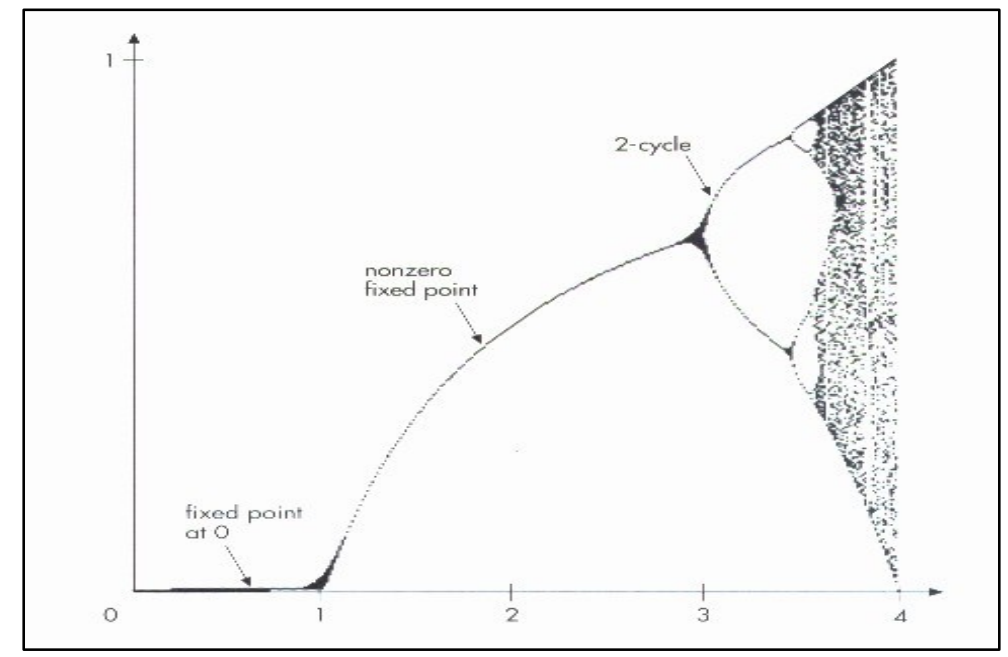

Fonte: Devaney e Choate (2000, p. 176)

Pode ser observado no mapeamento logístico um comportamento extremamente complexo que apresenta um padrão regular. Com a utilização de recurso computacional podem ser ampliadas as regiões próximas às bifurcações. As figuras 3 e 4 mostram o mapeamento logístico com valores de $\mathbf{k}$ variando, respectivamente, de 3 a 4 e de 3,83 e 3,855.

Figura 3: Mapeamento logístico com k variando entre 3 e 4

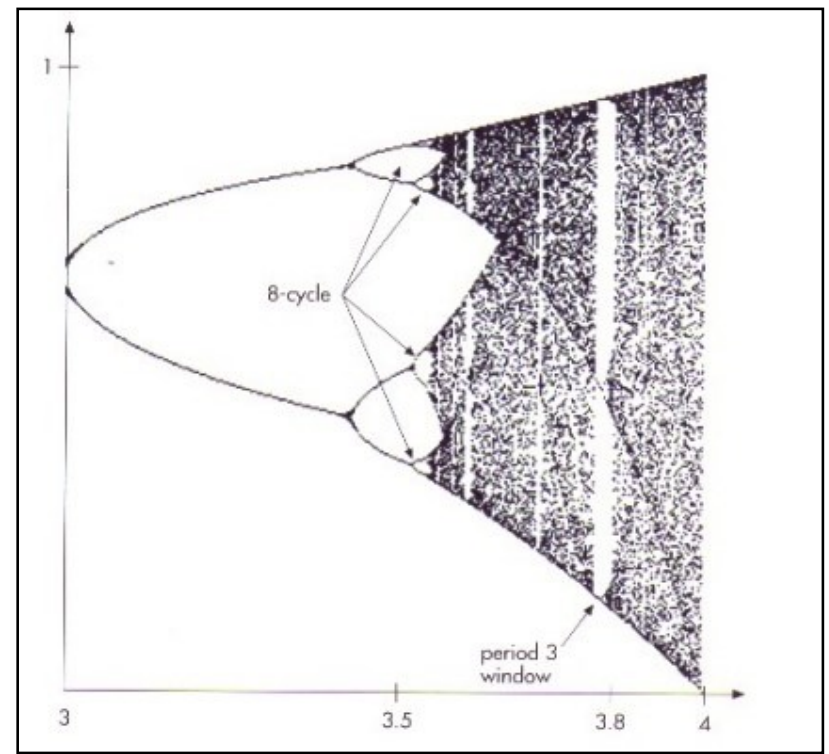

Fonte: Devaney e Choate (2000, p. 177) 
Figura 4: Mapeamento logístico com k variando entre 3,83 e 3,855

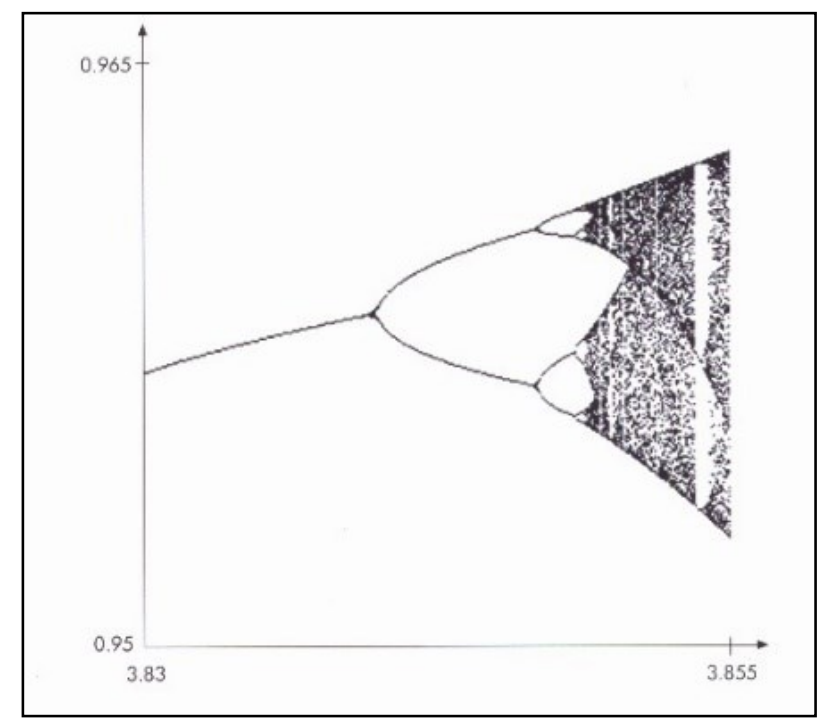

Fonte: Devaney e Choate (2000, p. 179)

As imagens mostradas nas figuras 3 e 4 são semelhantes ao diagrama original apresentado na figura 2. Podemos dizer, recorrendo à teoria dos fractais, que a estrutura apresenta a propriedade autossimilaridade, pois a estrutura repete-se em escalas cada vez mais finas.

O estudo do mapeamento logístico revela a fragilidade do equilíbrio da vida e possibilita trazer para o ensino da Matemática as inquietações relacionadas às questões ecológicas, que emergem no mundo onde vivemos.

\section{Considerações finais}

$\mathrm{Na}$ atualidade, frente aos problemas ambientais, torna-se urgente a abordagem de questões ecológicas, por exemplo, por meio do mapeamento logístico pesquisado pelo ecologista matemático Robert May, relacionado com os temas função quadrática e função composta. $\mathrm{O}$ estudo do mapeamento logístico, apresentando sensibilidade às condições iniciais, propriedade também conhecida como efeito borboleta, possibilita o entendimento de que o equilíbrio da vida é frágil. Desse modo, podem ser abordadas no ensino da Matemática as questões relacionadas com o pensamento ecológico, as quais emergem em diferentes áreas do conhecimento. Nos dizeres de Robert May (1992, p. 95, tradução nossa ${ }^{1}$ ):

não apenas na pesquisa [biológica], mas também no mundo cotidiano da política e da economia, nós todos estaríamos em melhor situação se um número maior de

\footnotetext{
${ }^{1}$ not only in [biological] research, but also in the everyday world of politics and economics, we would all be better off if more people realized that simple nonlinear systems do not necessarily possess simple dynamical properties.
} 
pessoas percebesse que sistemas não-lineares simples não possuem necessariamente propriedades dinâmicas simples.

$\mathrm{Na}$ contemporaneidade, a proposta de reduzir os fenômenos da natureza às leis matemáticas deterministas não é mais a única linha norteadora de todas as pesquisas científicas. As descobertas da ciência contemporânea têm mostrado que modelos deterministas, os quais parecem ser completamente precisos, não garantem previsibilidade completa, acontecendo a emergência de caos e ordem. Com a abordagem do mapeamento logístico, sendo focadas suas ligações com a teoria do caos, apresenta-se a possibilidade de abordar, na escola, a incerteza e as instabilidades que predominam no mundo onde vivemos, onde coexistem caos e ordem, intimamente ligados. Desse modo, torna-se possível incorporar no currículo da Matemática a visão de mundo norteadora das investigações no mundo da ciência contemporânea.

Para que as concepções da ciência contemporânea sejam assumidas na Educação Básica, não é necessária a substituição de conteúdos matemáticos que constituem a grade curricular, mas sim, a mudança no modo de abordá-los, o que significa assumir outra Filosofia do Currículo, sendo a Fenomenologia uma possibilidade.

$\mathrm{Na}$ atualidade, quando se dissemina a compreensão de que nosso planeta está agonizante e se reconhece que o ser humano, ao deixar de ser cuidado, está ameaçado, a postura fenomenológica apresenta-se como outra possibilidade de ver o homem e o mundo. Com as descobertas da ciência moderna a partir de Galileu e o consequente desenvolvimento de tecnologia, instaura-se o objetivo do máximo controle de tudo. Para a pergunta fundamental "O que é o homem?" a resposta predominante é "estar no controle da natureza". Apontando a ameaça que paira sobre o homem, frente às suas práticas predatórias, reflexo da crença na existência de recursos naturais ilimitados, Heidegger afirma que a essência do homem é cuidado. É urgente a incorporação nos currículos escolares de conteúdos da ciência contemporânea, privilegiando-se a atitude fenomenológica de perceber-se no mundo com os outros, de modo cuidadoso. Tal atitude se alinha com a visão de mundo que permeia a construção da ciência contemporânea norteada pela visão de mundo sistêmica, também conhecida como pensamento ecológico. 


\section{Referências}

BAIER, Tânia; BICUDO, Maria Aparecida Viggiani. Conteúdos Curriculares de Matemática na Educação Básica Brasileira: uma Análise Filosófica. In: SEMINÁRIO INTERNACIONAL DE PESQUISA EM EDUCAÇÃO MATEMÁTICA, 6. 2015, Pirenópolis. Anais... Pirenópolis: SBEM, 2015.

BAIER, Tânia. O nexo "Geometria Fractal - Produção da ciência contemporânea" tomado como núcleo do currículo de matemática do ensino básico. 2005. Tese (Doutorado em Educação Matemática) - Instituto de Geociências e Ciências Exatas, Universidade Estadual Paulista, Rio Claro, 2005.

BRANDÃO, Junito de Souza. Dicionário Mítico-etimológico da Mitologia Grega. Petrópolis: Vozes, 1991.

BRASIL. Ministério da Educação. Secretaria de Educação Fundamental. Parâmetros

Curriculares Nacionais: Matemática. Brasília: MEC/SEF, 1998.

BICUDO, Maria Aparecida Viggiani. O Papel do Educador. Nuances - Revista do Curso de Pedagogia. Presidente Prudente, SP, vol. IV, p. 20-24, set. 1998.

CAPRA, Fritjof. A Teia da Vida: Uma Nova Compreensão Científica dos Sistemas Vivos. 3. ed. São Paulo: Cultrix, 1998.

CAPRA, Fritjof. O Ponto de Mutação: a Ciência, a Sociedade e a Cultura emergente. 21. ed. São Paulo: Cultrix, 2000.

DEVANEY, Robert L.; CHOATE, Jonathan. Chaos: A Tool Kit of Dynamics Activities. Emeryville: Key Curriculum Press, 2000.

EKELAND, Ivar. A Matemática e o Imprevisto. Lisboa: Gradiva, 1993.

HEIDEGGER, Martin. Ser e Tempo - parte I. 2. ed. Petrópolis: Vozes, 1998.

LORENZ, Edward N. A Essência do Caos. Brasília: Ed. da UnB, 1996.

MAY, Robert. The Chaotic Rhythms of Life. In: HALL, Nina (Org.). The New Scientist Guide to Chaos. London: Penguin Books, 1992. 